\title{
Component transition and anticipatory contrast
}

\author{
BEN A. WILLIAMS \\ University of California, San Diego, La Jolla, California
}

\begin{abstract}
Previous research has demonstrated that contrast effects in multiple schedules occur because of variation in the reinforcement rate following the target components (anticipatory contrast). The present study assessed whether the contingency for transition to the following schedule was an important variable, on the premise that the discriminative cue for the following schedule should be a conditioned reinforcer that should suppress behavior when presented on a responseindependent basis. Strong contrast effects occurred even when the transition to the following schedule was response dependent, and these effects were comparable to those normally obtained with response-independent transitions.
\end{abstract}

Several studies, using both response-dependent (Williams, 1976a, 1979, 1981; Williams \& Wixted, 1986; Wilton \& Gay, 1969) and response-independent (Farley, 1980; Williams, 1976b) schedules have demonstrated that a major portion of the contrast effect in a multiple schedule is produced by variation in the reinforcement rate following a target component. Moreover, other investigators, using procedures very different from free-operant multiple schedules, have obtained similar results (Bacotti, 1976; Flaherty \& Checke, 1982; Flaherty \& Rowan, $1985,1986)$. A critical issue raised by these findings is the mechanism producing such a contrast effect. That is, is the effect (hereafter referred to as anticipatory contrast) adequately characterized as the "primitive" result of the relative reinforcement rate in the target component versus that which follows, or is it possible to identify some more molecular underlying process?

Previous research has attempted to identify the attribute of the following source of reinforcement that produced anticipatory contrast. Williams (1979, Experiment 2) presented pigeons with two separate target components, one of which was followed by a higher valued schedule and the other by extinction (EXT). When these two different following schedules were cued by different discriminative stimuli, large anticipatory contrast effects were observed; that is, response rates were higher in the target component followed by EXT. But when the same cue was used for the two different following schedules, resulting in high response rates in both the higher valued schedule and EXT, anticipatory contrast quickly disappeared. This finding demonstrates that it is not simply the occurrence or nonoccurrence of reinforcement in the following component that is the critical variable. Instead, anticipatory contrast seems to depend upon the "value" of the stimulus in the following component, where value is assessed by the response rate in the presence of the stimulus.

This research was supported by NSF research grant BNS 84-08878 to the University of California, San Diego. Requests for reprints should be addressed to Ben A. Williams, Department of Psychology, C-009, University of California, San Diego, La Jolla, CA 92093.
One interpretation of such effects of stimulus value assumes that the stimulus correlated with the following schedule possesses conditioned reinforcement properties. It is then possible to view a multiple schedule as similar to other procedures in which behavior is suppressed by the presentation of response-independent reinforcement (e.g., Rachlin \& Baum, 1972). The usual method for demonstrating free-reinforcement effects has been to add a variable-time (VT) schedule of free food to a variableinterval (VI) baseline; a multiple schedule is conceptually similar in the sense that the onset of the following component is presented independently of responding (because component transition is based only on the passage of time). Given that the stimulus correlated with the following component can be regarded as a conditioned reinforcer (when the following component has a higher value), this suggests that the response suppression that occurs in a target component followed by a higher valued component is due to the response-independent presentation of a conditioned reinforcer. Evidence that responseindependent conditioned reinforcers can suppress behavior in the same way as response-independent primary reinforcement was provided by Marr and Zeiler (1974).

The present experiment provides an assessment of the role of response-independent conditioned reinforcers as a component of anticipatory contrast. The critical test is whether anticipatory contrast occurs differently as a function of whether the transitions between components of a multiple schedule are response dependent or response independent. To make this comparison, a four-component multiple schedule was used, in which two target components with identical schedules were followed by components of either higher or lower value. In one set of conditions the transition between components was determined solely by the passage of time (component duration was set at $60 \mathrm{sec}$ ). For a second set of conditions a responsedependent schedule of component transition was superimposed on the food schedules, such that component transition occurred contiguous with the first response after the specified component duration had elapsed-a fixedinterval (FI) 60-sec schedule of component transition. If 
the contingency for conditioned reinforcement is an important variable, anticipatory contrast should occur in the first set of conditions, but the opposite effect (enhancement of response rates in the target component followed by the higher valued VI schedule) should occur in the second set.

A second variable was whether the schedule during the higher valued component was a signaled or an unsignaled VI schedule. If the relation between behavior in the target component and the stimulus correlated with the following schedule is important, a following component with an unsignaled high-valued VI schedule should produce greater contrast effects than when the following component involves a signaled VI of comparable value. This should be true because the signaled VI schedule entails that the cue correlated with EXT will be present for the great majority of time, which further entails that the EXT cue will also be present at a point of component transition on most occasions. Thus, the contingency between responding during the target component and the conditioned reinforcers during the following component will be more clear-cut with the unsignaled VI schedule.

\section{METHOD}

\section{Subjects}

Four White Carneau pigeons were maintained at $80 \%$ of their freefeeding body weights by additional feeding after the end of the daily experimental sessions. All had extensive histories, including several previous studies of behavioral contrast (Williams, 1976a, 1979, 1981).

\section{Apparatus}

A standard one-key operant pigeon chamber was used, which is described in detail by Williams (1981).

\section{Procedure}

The present study was an extension of a previous report (Williams, 1981, Experiment 1) involving a recycling four-component multiple schedule. Two components, cued by three vertical white lines and a white circle, were correlated with identical but independent VI 3-min schedules, which remained unchanged throughout training. The schedules surrounding the two target components were EXT, always correlated with a diffuse red keylight; a VI 1-min schedule, always correlated with a diffuse blue keylight; or a signaled (sig) VI 1-min schedule, in which the stimulus was the red keylight until the reinforcer became available, at which time the stimulus was changed to blue until the next peck obtained the reinforcer.

Because the subjects had been exposed to a long series of conditions in prior studies, Condition 1 of the present study was a baseline condition in which the two target components were followed by the same conditions. Thus, both the vertical lines and the circle were preceded and followed by EXT, always correlated with the diffuse red light. The sequence was then changed to one in which the lines and the circle were preceded equally often by a VI 1-min or an EXT component, but were followed exclusively by one or the other, with this relationship reversed for some conditions. The sequence for Condition 2 was VI-3 (vertical lines), EXT, VI-3 (vertical lines), EXT, VI-3 (circle), sig VI-1, VI-3 (circle), sig VI-1, and then the whole sequence recycled. This sequence was also used for Condition 3, and was then changed to one in which the positions of the circle and the vertical lines were reversed (Condition 4). During Conditions 5 and 6, the reversed sequence continued but with the sig VI-1 schedule replaced by an unsignaled VI-1 schedule. The entire sequence of conditions is shown in Figure 1.

Component duration throughout the study was nominally $60 \mathrm{sec}$. The critical variable of interest was the contingency determining component transition. For Conditions 1, 2, and 6, the transitions between components were response independent and component duration was always $60 \mathrm{sec}$. For the remaining three conditions, the transition from both the circle and the vertical lines was dependent on responding, such that the first peck after the required time had elapsed $(60 \mathrm{sec})$ produced the transition to VI 1-min, sig VI 1-min, or EXT. No response requirement was imposed for the transition from either the VI 1-min or EXT to the VI 3-min components. The number of sessions per condition is shown in Figure 1.

\section{RESULTS}

Figure 1 plots the response rates during the two target components (the circle and the vertical lines) that were correlated with identical VI 3-min food schedules. Dur-

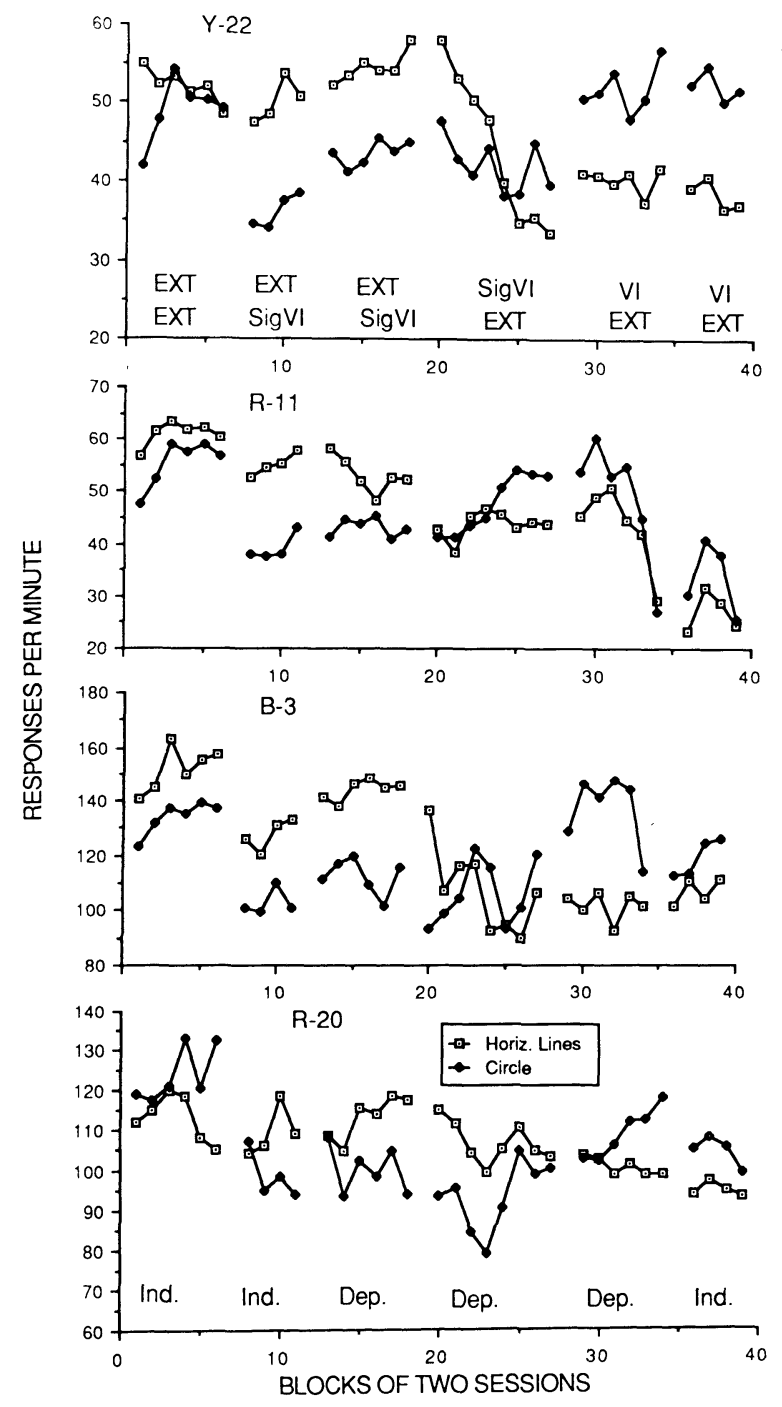

Figure 1. Response rates during the target components with identical VI 3-min schedules. The schedules following the two target components are shown at the bottom of the panel for Subject Y-22, with the top schedule designation following the vertical lines and the bottom designation following the circle. Whether the transition to the following components was response independent or response dependent is shown at the bottom of the panel for Subject R-20. 
ing the first condition, in which both target components were followed (and preceded) by EXT, there were no consistent differences in response rates between the two components. For Subject Y-22 the rates in the two components were essentially equal by the end of Condition 1; for Subjects R-11 and B-3 response rates were higher during the lines component than during the circle component; and for Subject R-20, response rates were higher during the circle component than during the lines component. Presumably, such effects reflect different stimulus biases for different subjects.

During the second condition, in which the lines were followed by EXT and the circle by the higher valued sig VI schedule, all subjects produced higher response rates during the lines component, thus demonstrating an anticipatory contrast effect like that shown in previous studies. The first test of the effects of the response contingency for transition to the following component is then provided by a comparison of Conditions 2 and 3, because during Condition 3 the transition to the following component was made response dependent. Despite the change in the contingency for component transition, there was no consistent change in the pattern of response rates in the two target components. There was some reduction in the difference between the target components for Subject R-11, but for Subjects B-3 and R-20 there was a small increase in the difference.

Because the differences seen in Condition 3 could be due simply to the continuation of the differences established in Condition 2, the most powerful test of the role of response contingency occurred during Condition 4 , in which the schedules following the two target components were reversed but the response-dependent componenttransition contingency was maintained. Three of the 4 subjects reversed readily, whereas the response rates of the 4th (Subject R-20) converged. Thus, anticipatory contrast was reestablished after the reversal in reinforcement rates, even with the response-dependent component transitions.

Conditions 5 and 6 involved a change from a sig VI schedule to an unsignaled VI schedule following the circle. Condition 5 continued the response contingency during the target components for component transition, whereas Condition 6 removed that contingency. The effect of the change from the sig VI schedule to an unsignaled VI schedule in Condition 5 was to increase the difference between the two target components for 3 of the 4 subjects, although this probably was due simply to continued training after the reversal in the following schedules. For the 4th subject (R-11), the difference between the target components converged, but this was correlated with a substantial reduction in response rates in all components, making the effect difficult to interpret. Finally, the change to Condition 7 produced no consistent effect, indicating once again that the contingency for component transition was not a controlling variable.

The effects of the contingency for component transition can be summarized by the mean differences in response rates between the two target components (that fol- lowed by the higher valued schedule was always lower) during the last four sessions of those conditions that allow a direct comparison between the response-independent and response-dependent component transitions. For Conditions 2 and 3, which allow a comparison with the sig VI schedule as the higher valued following schedule, the mean difference when component transition was responseindependent was 19.7 responses per minute, whereas that for response-dependent transition was 18.8. For Condition 6 versus Condition 7, when the higher valued schedule was the unsignaled VI schedule, the corresponding differences were 14.3 versus 11.2. For neither comparison did the differences as a function of the type of component transition approach statistical significance.

\section{DISCUSSION}

The results of the present study provide no evidence for an effect of the contingency for transition to the following component. No consistent differences in the degree of anticipatory contrast occurred as a function of whether transition to the different following schedules was response dependent or response independent, although this generalization must be qualified because only a few sessions were conducted for each condition and behavior was somewhat variable. Had more sessions per condition been conducted, it is possible that some difference as a function of the response contingency would have become apparent. However, the results clearly show that anticipatory contrast does not depend upon the transition to the following components being response independent. Not only was there no consistent change in the degree of contrast between conditions when this contingency was changed (Condition 2 vs. Condition 3 and Condition 5 vs. Condition 6), but the pattern of anticipatory contrast was also shown to recover after a reversal of the target component even when the transitions to the following schedules were response dependent (Condition 4). Thus, the hypothesis that anticipatory contrast is due to response suppression caused by responseindependent conditioned reinforcement must be rejected.

The failure to detect any effect of response contingency on the degree of anticipatory contrast is somewhat surprising, given the results of Marr and Zeiler (1974), who found substantial differences in the rates of responding to a VI food schedule as a function of whether a brief stimulus otherwise paired with food was presented on a response-independent or response-dependent basis. Substantially higher response rates occurred in their study when the conditioned reinforcer was response dependent; moreover, when the conditioned reinforcer was response independent, the rates of responding were lower than during baseline, when no conditioned reinforcers were presented (but with clear effects for only 1 of 2 subjects). Their study thus provides evidence that the effect of the response contingency for conditioned reinforcers is similar to that for primary reinforcers. Why similar effects did not occur in the present study remains unclear, but several major differences between Marr and Zeiler's procedure and that of the present study can be noted. Not only was their conditioned reinforcer more strongly correlated with the occurrence of food, but their food schedule, upon which the conditioned reinforcement schedule was superimposed, was much leaner; these factors should act together to make the effects of the conditioned reinforcer more evident. In any event, the issue is not whether conditioned reinforcers can strongly affect behavior; they obviously do under some circumstances (e.g., Royalty, Williams, \& Fantino, 1987). The issue is whether the response contingency for the possible conditioned reinforcement effects of component transition is the cause of anticipatory contrast. The present data show clearly that this is not the case.

\section{REFERENCES}

Bacotri, A. V. (1976). Home cage feeding time controls responding under multiple schedules. Animal Learning \& Behavior, 4, 41-44. 
FARLEY, J. (1980). Automaintenance, contrast, and contingencies: Effects of local vs. overall, and prior vs. impending reinforcement contrast. Learning \& Motivation, 11, 19048.

FlaherTy, C. F., \& CheCKE, S. (1982). Anticipation of incentive gain. Animal Learning \& Behavior, 10, 177-182.

Flaherty, C. F., \& Rowan, G. A. (1985). Anticipatory contrast: Within-subjects analysis. Animal Learning \& Behavior, 13, 2-5.

FlaherTy, C. F., \& Rowan, G. A. (1986). Successive, simultaneous, and anticipatory contrast in the consumption of saccharin solutions. Journal of Experimental Psychology: Animal Behavior Processes, 12, 381-393.

MARR, M. J., \& ZEILER, M. D. (1974). Schedules of responseindependent conditioned reinforcement. Journal of the Experimental Analysis of Behavior, 21, 433-444.

RACHLIN, H., \& BAUM, W. M. (1972). Effects of alternative reinforcement: Does the source matter? Journal of the Experimental Analysis of Behavior, 18, 231-241.

Royalty, P., Williams, B. A., \& Fantino, E. (1987). Effects of delayed conditioned reinforcement in chain schedules. Journal of the Experimental Analysis of Behavior, 47, 41-56.
Williams, B. A. (1976a). Behavioral contrast as a function of the temporal location of reinforcement. Journal of the Experimental Analysis of Behavior, 26, 57-64.

Williams, B. A. (1976b). Elicited responding to signals for reinforcement: The effects of overall versus local changes in reinforcement probability. Journal of the Experimental Analysis of Behavior, 26, 213-220.

Williams, B. A. (1979). Contrast, component duration, and the following schedule of reinforcement. Journal of Experimental Psychology: Animal Behavior Processes, 5, 379-396.

Williams, B. A. (1981). The following schedule of reinforcement as a fundamental determinant of steady-state contrast in multiple schedules. Journal of the Experimental Analysis of Behavior, 35, 293-310.

Williams, B. A., \& WiXTED, J. T. (1986). An equation for behavioral contrast. Journal of the Experimental Analysis of Behavior, 45, 47-62.

Wilton, R. N., \& GAY, R. A. (1969). Behavioral contrast in one component of a multiple schedule as a function of the reinforcement conditions operating in the following component. Journal of the Experimental Analysis of Behavior, 7, 339-346. 